\title{
TCF7L2 promotes beta cell regeneration in human and mouse pancreas
}

\author{
L. Shu • K. Zien • G. Gutjahr • J. Oberholzer • F. Pattou • \\ J. Kerr-Conte $\cdot$ K. Maedler
}

Received: 10 February 2012 /Accepted: 17 July 2012 / Published online: 4 September 2012

(C) Springer-Verlag 2012

\begin{abstract}
Aims/hypothesis Diabetes is characterised by loss and dysfunction of the beta cell. A major goal of diabetes therapy is to promote the formation of new beta cells. Polymorphisms of T cell factor 7-like 2 (TCF7L2) are associated with type 2 diabetes, negatively regulating beta cell survival and function. Here, we provide evidence for a role of TCF7L2 in beta cell proliferation and regeneration.

Methods Pancreatic sections from three mouse models (high-fat diet, exendin-4 and streptozotocin-treated mice) and from healthy individuals and patients with type 2 diabetes were used to investigate the association of beta cell regeneration and TCF7L2 levels. To analyse a direct effect
\end{abstract}

Electronic supplementary material The online version of this article (doi:10.1007/s00125-012-2693-z) contains peer-reviewed but unedited supplementary material, which is available to authorised users.

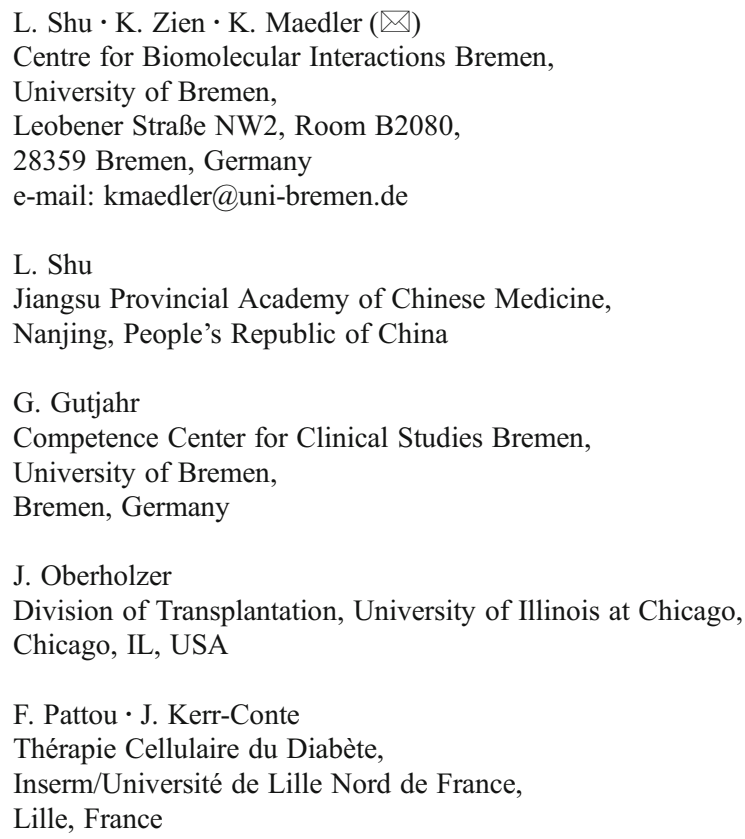

of TCF7L2 on duct cell to beta cell conversion, TCF7L2 was overexpressed in isolated exocrine cells.

Results TCF7L2 levels correlated with beta cell compensation during high-fat diet feeding. TCF7L2 was increased together with pancreatic duct cell proliferation and differentiation. Small islet-like cell clusters (ICCs) that contained TCF7L2 originated in the vicinity of the ductal epithelium. In human isolated exocrine tissue, TCF $7 L 2$ overexpression induced proliferation of pancreatic duct cells and ICC formation next to duct cells, an effect dependent on the JAK2/ STAT3 pathway.

Conclusions/interpretation The present study demonstrates that TCF7L2 overexpression fosters beta cell regeneration. Our findings imply correlation of TCF7L2 levels and new beta cell formation.

Keywords Beta cell regeneration · Diabetes $\cdot$ Islets $\cdot$ TCF7L2

$\begin{array}{ll}\text { Abbreviations } \\ \text { CK19 } & \text { Cytokeratin-19 } \\ \text { GFP } & \text { Green fluorescent protein } \\ \text { GIP } & \text { Gastric inhibitory polypeptide } \\ \text { GLP1 } & \text { Glucagon-like peptide-1 } \\ \text { HFD } & \text { High-fat diet } \\ \text { ICC } & \text { Islet-like cell cluster } \\ \text { JAK2 } & \text { Janus kinase 2 } \\ \text { ND } & \text { Normal diet } \\ \text { NGN3 } & \text { Neurogenin 3 } \\ \text { p-AKT } & \text { Phosphorylated AKT } \\ \text { PDX1 } & \text { Pancreatic and duodenal homeobox 1 } \\ \text { p-STAT } & \text { Phosphorylated signal transducer and activator } \\ & \text { of transcription 3 } \\ \text { siRNA } & \text { Small interfering RNA } \\ \text { STAT3 } & \text { Signal transducer and activator of transcription 3 } \\ \text { STZ } & \text { Streptozotocin } \\ \text { TCF } & \text { T cell factor } \\ \text { TCF7L2 } & \text { T cell factor 7-like 2 }\end{array}$




\section{Introduction}

Worldwide studies have reported a strong linkage of single nucleotide polymorphisms in the TCF7L2 gene with type 2 diabetes [1]. T cell factor 7-like 2 (TCF7L2) is a transcription factor and major effector of Wnt signalling that is found in several tissues, including the gut and pancreas. Wnt signalling is essential for cell development and regeneration. In pancreatic beta cells, it fosters beta cell proliferation, insulin secretion [2], neonatal growth and regeneration [3].

TCF7L2 itself promotes beta cell proliferation, protects against apoptosis and improves insulin secretion [4-6]. TCF7L2 knockout islets show impaired glucose-, glucagon-like peptide-1 (GLP1)- and gastric inhibitory polypeptide (GIP, also known as glucose-dependent insulinotropic peptide)-stimulated insulin secretion [4]. In addition, beta cell-specific Tcf7l2 knockout mice display impaired glucose tolerance [7].

As one important mechanism of the deleterious effect of TCF7L2 loss in the beta cell, we have previously detected the parallel downregulation of beta cell GIP and GLP receptors [6], which may explain the limited incretin response in patients with the TCF7L2 risk alleles [8]. The two incretin hormones GLP1 and GIP are important targets for diabetes therapy because of their ability to potentiate glucose-stimulated insulin secretion, as well as to promote beta cell proliferation, beta cell neogenesis and survival in animal models [9].

In line with these studies, in rats with TCF7L2 knockdown by specific Tcf7l2 morpholino-oligonucleotides, the process of beta cell regeneration was significantly inhibited [3]. GLP1 and TCF7L2 share common pathways and both promote beta cell survival. In the current study, we investigated whether TCF7L2 itself can promote beta cell regeneration and neogenesis.

Three mouse models of beta cell renewal and regeneration, including high-fat diet (HFD)/high-sucrose diet, exendin-4 and streptozotocin (STZ)-treated mice [10-12], were investigated to evaluate the effects of TCF7L2 on new beta cell formation. We aimed to clarify how TCF7L2 levels change during the compensatory adaptation of beta cell mass during HFD feeding and later during diabetes progression. Using the HFD mouse model, which shows progression from metabolically healthy obesity to impaired glucose tolerance and severe diabetes, enabled us to directly correlate TCF7L2 production with glycaemia and diabetes.

\section{Methods}

Animals C57BL/6J mice (Jackson Laboratories, Bar Harbor, ME, USA) aged 6 weeks or 14 months were fed an HFD/high-sucrose diet ('Surwit' Research Diets, New Brunswick, NJ, USA) [13] or normal diet (ND; Harlan
Teklad Rodent Diet 8604) for 4-16 weeks. Exendin-4 (10 nmol/kg; Sigma) or PBS was injected i.p. daily for 7 days, or a single dose of $90 \mathrm{mg} / \mathrm{kg}$ freshly prepared STZ in citrate buffer ( $\mathrm{pH} 4.5)$ or citrate buffer was used as a control. All animals were housed in a temperaturecontrolled room with a $12 \mathrm{~h}$ light/dark cycle and were allowed free access to food and water in agreement with National Institutes of Health animal care guidelines $\S 8$ of the German animal protection law.

Cell culture Isolated mouse and human pancreatic exocrine cells from islet isolations [14] were cultured on extracellular matrix-coated dishes (Novamed, Jerusalem, Israel) in DMEM supplemented with $10 \%$ FCS and penicillin-streptomycin (1\%), with or without exposure to the Janus kinase 2 (JAK2) inhibitor AG490 (20 mmol/l; Sigma, St Louis, MO, USA). Human islets were isolated from the pancreases of five healthy organ donors at the University of Illinois at Chicago (IL, USA) and from Inserm/Université de Lille, Thérapie Cellulaire du Diabète (France) and cultured as previously described [15].

TCF7L2 plasmid and siRNA transfection Isolated islets or exocrine cells were exposed to transfection $\mathrm{Ca}^{2+}$ - Krebs Ringer's/HEPES medium. After $1 \mathrm{~h}$ incubation, lipoplexes (Lipofectamine 2000; Invitrogen, Carlsbad, CA, USA)/DNA ratio 2.5:1, $3 \mu \mathrm{g}$ DNA of TCF7L2 plasmid (full-length TCF7L2 from the Full-Length Mammalian Gene Collection, Invitrogen), or a pCMV-green fluorescent protein (GFP) control plasmid or $50 \mathrm{nM}$ small interfering RNA (siRNA) to TCF7L2 (RNAs of 21 nucleotides, designed to target human TCF7L2; Stealth Select RNAi, Invitrogen) and scramble siRNA (Dharmacon, Lafayette, CO, USA) were added to transfect the cells as previously described $[15,16]$.

Immunohistochemistry Pancreatic tissue and cultured mouse islets and isolated human pancreatic exocrine cells were processed as previously described [6]. For details of antibodies and staining, see the electronic supplementary material (ESM). The University of Bremen ethics committee approved all studies involving human cells and organ donors.

Analysis of beta cell mass Beta cell mass was measured as previously described [13]. In brief, ten sections (spanning the width of the pancreas, which was cut along the head-tail axis) from each pancreas were stained with anti-mouse insulin antibody (Dako, Hamburg, Germany) and scanned with a Nikon MEA53200 (Nikon, Dusseldorf, Germany) microscope. The cross-sectional areas of pancreas and beta cells were determined by NIS-Elements software (Nikon). Beta cell mass/pancreas was estimated by the product of the relative cross-sectional area of beta cells per total tissue and the weight of the pancreas. 
$R N A$ extraction and RT-PCR Total RNA was isolated from cultured human pancreatic exocrine cells as previously described [14]. For quantitative analysis, we used the Applied Biosystems StepOne Real-Time PCR system (Applied Biosystems, Carlsbad, CA, USA) with a commercial kit (Power SYBR Green PCR Master Mix; Applied Biosystems). For signal transducer and activator of transcription 3 (STAT3) analysis, TaqMan gene expression assays (Fast Universal PCR Master Mix; Applied Biosystems) were used. The primers are described in the ESM.

Western blot analysis Isolated cultured pancreatic exocrine cells were washed in PBS and lysed. Polyvinylidene fluoride filters were incubated with rabbit anti-TCF7L2 (clone C9B9, \#2565), rabbit anti-STAT3 (\#9132), rabbit antiphosphorylated (p)-STAT3 (Tyr705, \#9131), rabbit antiactin (\#4967) and rabbit anti-p-AKT (Serine473, \#9271) (all Cell Signaling, Danvers, MA, USA), followed by incu- bation with horseradish-peroxidase-linked IgG peroxidase. Band density was analysed using DocIT LS image acquisition 6.6a (UVP BioImaging Systems, Upland, CA, USA).

Statistical analysis Samples were evaluated in a randomised manner by a single investigator (L.S.) who was blinded to the treatment conditions. Data are presented as means \pm SE. Mean differences were tested by Student's $t$ test. Bonferroni correction was used to account for multiplicity in the treated cells in vitro and mice in vivo. Because of the skew of the data, nonparametric methods were also applied to all TCF7L2 expression analyses. Robust median regression models were used to describe $T C F 7 L 2$ expression, and the significance of differences was assessed with the Mann-Whitney $U$ test. Immunostainings were analysed by resampling tests that consider all combinations of the possible permutations within each donor. Comparisons between GFP, GLP1 and TCF overproduction groups were performed by Kruskal-
Fig. 1 Tcf $7 l 2$ expression increases with adaptive beta cell compensation and is lost with diabetes progression. $\mathrm{C} 57 \mathrm{Bl} / 6$ mice were fed an ND or HFD/ high-sucrose diet for 16 weeks. i.p. GTT with $1 \mathrm{~g} / \mathrm{kg}$ body weight of glucose after 4 (a), 8 (b), 12 (c) and 16 weeks (d) of feeding. (e) TCF7L2 protein, insulin and DAPI levels in pancreatic sections from the same mice. (f) Quantification of TCF7L2-positive beta cells, shown as a mean percentage of TCF7L2/insulin-positive cells \pm SE. Results are from at least 12 mice in each group from three independent experiments. Values are representative of three or four slides spanning the whole pancreas of each mouse and four mice per group. A total of $1,925 \pm 376$ beta cells were counted per treatment group for each analyte. ${ }^{*} p<0.05$, HFD compared with ND. Black squares/white bars, ND; white squares/grey bars, HFD
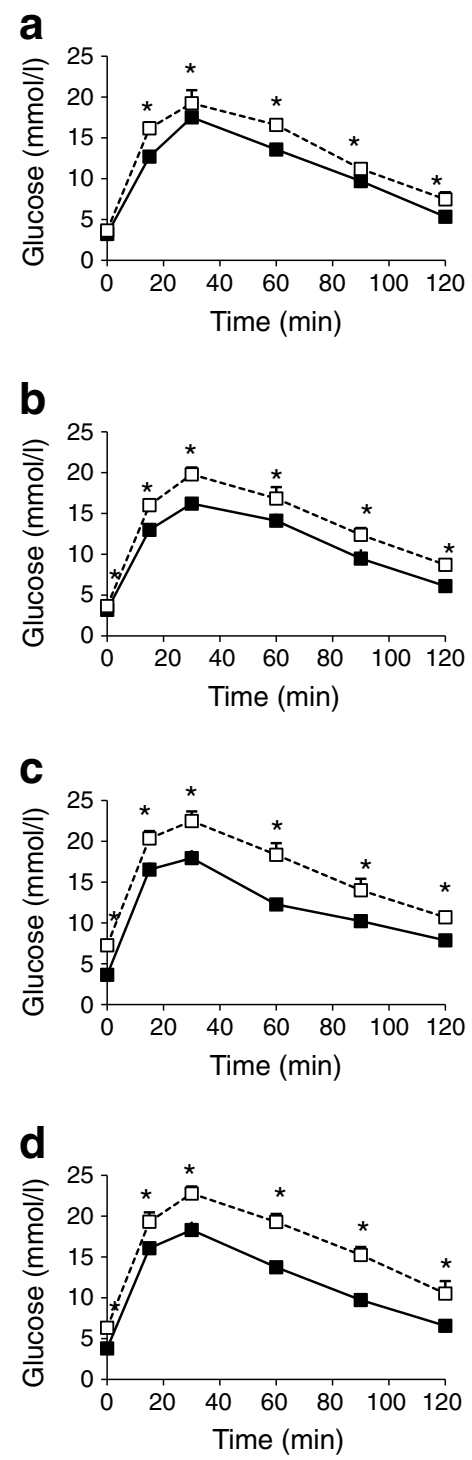
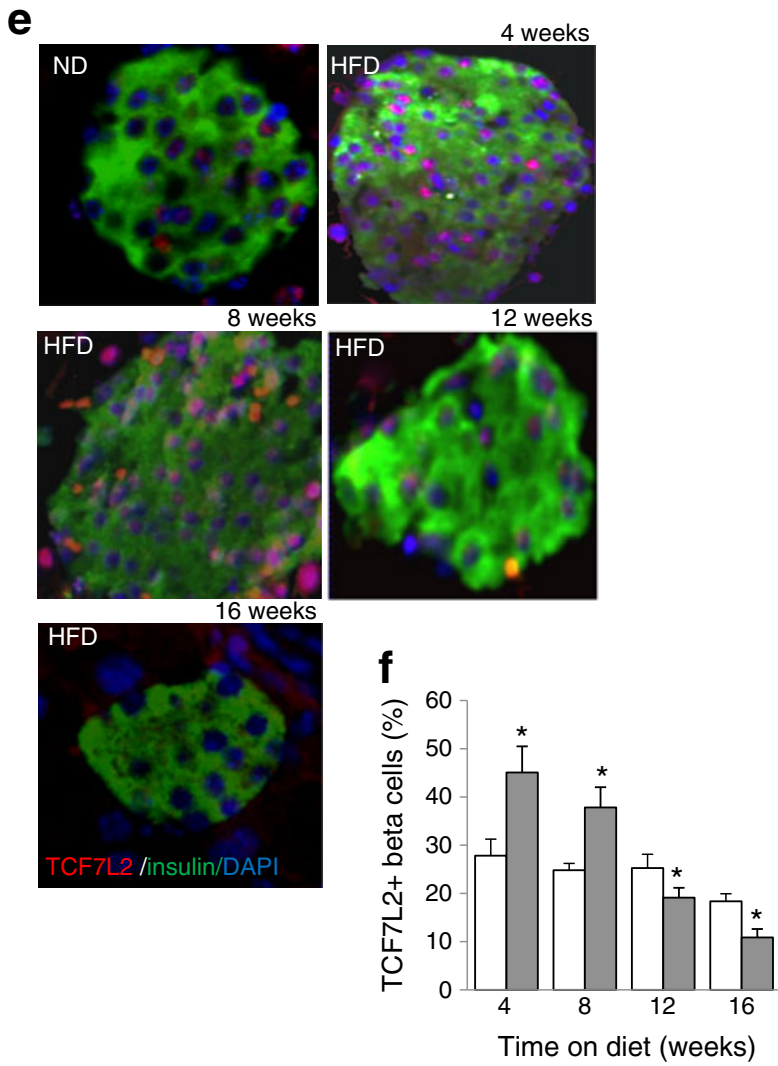
Wallis tests; multiple-adjustment $p$ values were calculated by the closed testing principle.

\section{Results}

TCF7L2 levels increase with adaptive beta cell compensation and are lost with diabetes progression $\mathrm{C} 57 \mathrm{Bl} / 6$ mice fed an HFD showed impaired glucose tolerance after 4 weeks, which worsened with time on the diet (Fig. 1a-d). Impaired fasting glucose and hyperinsulinaemia became apparent after 8 weeks, hyperglycaemia after 12 weeks and beta cell apoptosis after 16 weeks of diet, as previously reported [17]. Pancreatic TCF7L2 levels were measured by immunostaining during the 16 weeks of the diet. Increased intra-islet TCF7L2 levels were observed in HFD-treated mice, but only after 4 and 8 weeks of feeding (1.6- and 1.5-fold more TCF7L2-positive beta cells in HFD compared with ND control mice after 4 and 8 weeks of diet, respectively, $p<0.05, n=12$; Fig. 1e, f). At this time, beta cell mass was increased compared with ND-fed mice (as previously shown [17]). In contrast, TCF7L2 levels decreased after 12 weeks of HFD feeding $(24.5 \%$ and $46.1 \%$ decrease in
TCF7L2-positive beta cells after 12 and 16 weeks of HFD compared with ND, respectively, $p<0.05, n=12$; Fig. 1e, f), which occurred in parallel with hyperglycaemia and the development of beta cell failure in mice fed an HFD for 12 and 16 weeks.

TCF7L2 levels decrease during diabetes progression at an older age It has previously been reported that the capacity to expand beta cell mass declines with age because of reduced beta cell proliferation and a decreased capacity of beta cells to regenerate [12]. Similar results were found in the current study. Glucose tolerance was impaired in response to 8 weeks of HFD feeding in young mice when the diet was started at the age of 6 weeks, compared with ND $(p<0.05, n=9$, Fig. 2a). When HFD feeding was started at the age of 14 months, glucose levels during the i.p. GTT were all significantly higher in the old mice compared with the young HFD mice $(p<0.05, n=9$; Fig. $2 \mathrm{a})$. While beta cell mass was increased twofold in young HFD-fed mice $(p<0.05$, compared with ND), this increase in beta cell mass did not occur in old mice (Fig. 2b). This change in beta cell mass can be explained by decreased beta cell turnover at an older age. Beta cell proliferation increased in response to
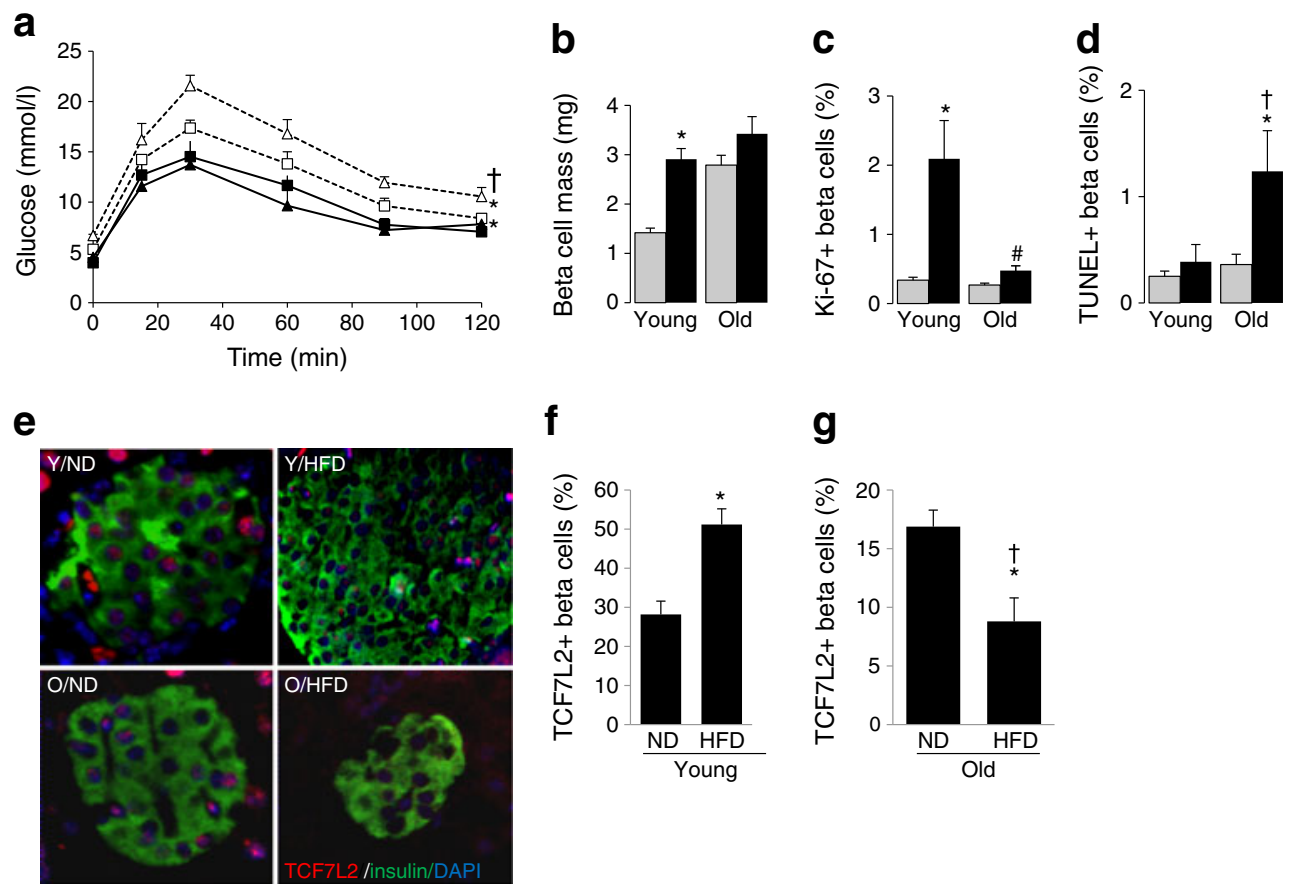

f

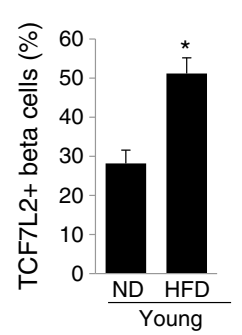

g

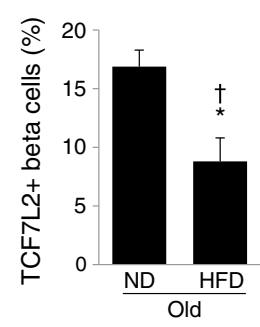

Fig. 2 TCF7L2 production decreases during diabetes progression in old mice. Six-week-old (young) and 14-month-old (old) male C57BL/ 6 mice were fed either an ND or HFD for 8 weeks. (a) i.p. GTT with $1 \mathrm{~g} / \mathrm{kg}$ body weight of glucose after 8 weeks of feeding. Black squares, young ND; white squares, young HFD; black triangles, old ND; white triangles, old HFD. (b) Beta cell mass as a product of pancreas mass and insulin-positive area divided by section area, (c) beta cell proliferation analysed by Ki67/insulin staining and (d) beta cell apoptosis by TUNEL assay and insulin. Grey bars, ND, black bars, HFD. (e)
Pancreatic sections were triple stained for TCF7L2, insulin and DAPI in young (Y) and old (O) mice. (f, g) Quantification of TCF7L2positive beta cells shown as mean percentage of TCF7L2/insulinpositive cells \pm SE. Results are from nine mice with each treatment from three independent experiments. For beta cell mass, ten sections spanning the whole pancreas were analysed per mouse. A total of $2,062 \pm 686$ beta cells were counted per mouse for each analyte. ${ }^{*} p<$ 0.05 , HFD compared with ND mice of the same age; ${ }^{\dagger} p<0.05$, HFD old compared with HFD young mice 
HFD in young mice ( $p<0.05$, Fig. $2 c)$ and remained unchanged in old mice under the HFD, but beta cell apoptosis increased in the old mice $(p<0.05$, Fig. $2 \mathrm{~d})$ and remained unchanged in the young mice under the HFD, in agreement with an earlier study [12]. While 8 weeks of HFD feeding caused upregulation of TCF7L2 in young mice (1.9-fold induction compared with young mice fed an $\mathrm{ND}, p<0.05$, Fig. 2e-g), TCF7L2 was significantly downregulated in old HFD mice (2.2-fold reduction compared with old mice fed an ND, $p<0.05$, Fig. 2e-g). In contrast, 12 weeks of HFD feeding of 6-week-old mice ('young') has been reported to result in decreased proliferation [13] and reduced TCF7L2 levels, indicating that TCF7L2 levels correlate with critical changes in beta cell adaptation.

Beta cell replication and increased TCF7L2 levels in STZ and exendin-4 injected mice Since TCF7L2 levels correlated with the compensation capacity in HFD-fed mice, we investigated whether this increase also occurs in mouse models of beta cell regeneration. Two standard regeneration models were used: (1) a single injection of STZ (90 $\mathrm{mg} / \mathrm{kg}$ body weight); and (2) daily injections of exendin-4 (10 nmol $/ \mathrm{kg})$ for 1 week [12]. Exendin-4 stimulates both beta cell replication and neogenesis [18], and a single dose of the beta cell toxin STZ in mice leads to $50 \%$ loss of beta cells, together with an increase in beta cell proliferation and regeneration at 7 days after the STZ injection [12].

STZ resulted in hyperglycaemia 4 days after the single injection (Fig. 3a), and increased fasting glucose (Fig. 3c) and $45 \%$ loss of beta cell mass after 7 days $(p<0.05$; Fig. 3e). In the exendin-4-treated mice, glucose levels were lower than in the control group (Fig. 3b), mice did not show significant changes in fasting glucose (Fig. 3d) and beta cell mass was 1.5 -fold increased after 7 days $(p<0.05$ compared with control, $n=10$; Fig. 3e).

Both STZ and exendin- 4 injection led to increased beta cell proliferation (3.5- and 3.8-fold induction of beta cell proliferation, respectively, compared with vehicle control, $p<0.05$; Fig. 3f, h, i). This was accompanied by increased intra-islet TCF7L2 levels both in STZ- and exendin-4-treated mice (twoand 1.8-fold more TCF7L2-positive beta cells in STZ- and exendin-4-treated mice, respectively, compared with vehicletreated control mice, $p<0.05$; Fig. $3 \mathrm{~g}, \mathrm{j}$, k).

Increased TCF7L2 is associated with ductal epithelial cell proliferation and differentiation in STZ- and exendin-4treated mice Since we saw an association of TCF7L2 with

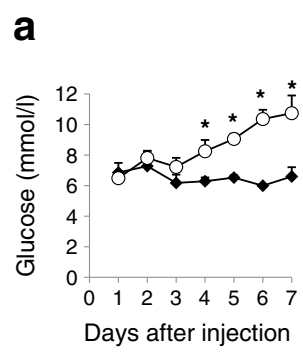

b

f
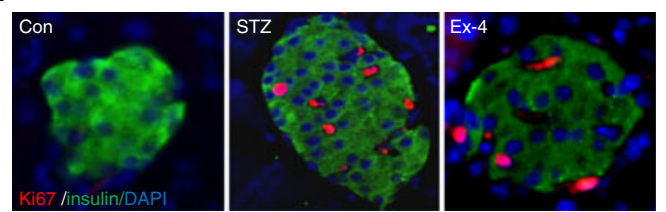

g
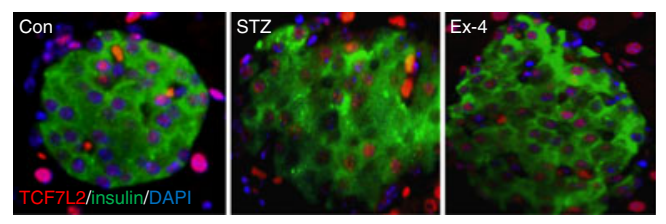
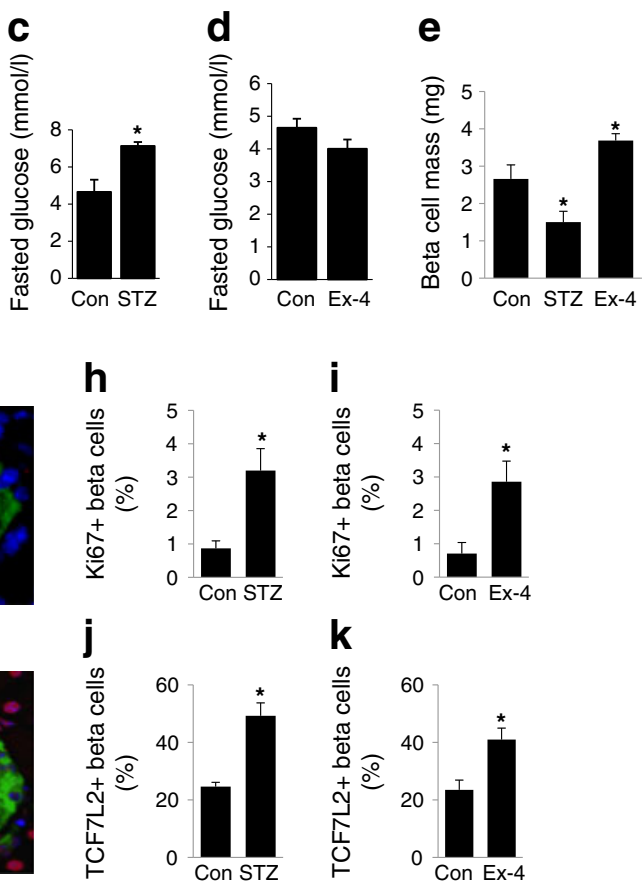

Fig. 3 Beta cell replication and increased TCF7L2 expression in STZ and exendin-4 injected mice. $\mathrm{C} 57 \mathrm{Bl} / 6$ mice were injected i.p. with either exendin-4 (Ex-4, $10 \mathrm{nmol} / \mathrm{kg})$, STZ $(90 \mathrm{mg} / \mathrm{kg})$ or vehicle (control, Con). Fed blood glucose levels were measured daily (a, b) and fasting blood glucose levels after 1 week (c, d). Black diamonds, control; white circles, STZ; white diamonds, exendin-4. (e) Analysis of beta cell mass at 1 week after treatment. (f) Percentage of Ki67-positive beta cells of exendin-4- and STZ-treated mice quantified from triple stainings for Ki67/insulin/DAPI. (g) TCF7L2 quantification in pancreatic sections of exendin-4- and STZ-treated mice by triple staining for TCF7L2/insulin/DAPI. Results are from ten mice each treatment from three independent experiments. Values are representative of five or six slides spanning the whole pancreas of each mouse. A total of $4,463 \pm$ 377 beta cells were counted per mouse for each analyte. ${ }^{*} p<0.05$ compared with vehicle control 
beta cell proliferation in the pancreas, we next investigated whether there is beta cell neogenesis from ductal cells in STZ- and exendin-4-treated mice and whether this is paralleled by changes in TCF7L2 production.

As displayed in Fig. 4a, there were 3.75- and 3.12-fold more proliferating ductal cells (Ki67 and cytokeratin-19 [CK19] double-positive cells) in STZ- and exendin-4treated mice compared with control mice $(p<0.005, n=10)$.

The presence of pancreatic and duodenal homeobox 1 (PDX1)-positive cells in the pancreatic ductal epithelium has been demonstrated in rodent models following partial pancreatectomy [19], serving as a marker for new beta cell formation. We quantified PDX1/CK19 doublepositive ductal cells by immunofluorescent staining in pancreatic sections from STZ- and exendin-4-treated mice (Fig. 4b). This revealed a significantly enhanced number of PDX1-positive ductal cells in STZ- and exendin-4-treated mice, while ductal PDX1 was almost absent in control mice (8.3- and 7.2-fold more PDX1/ CK19 double-positive cells in STZ- and exendin-4treated mice, respectively, compared with control mice, $p<0.005$; Fig. 4b).

Newly formed beta cells from ductal cells should express beta cell and ductal cell markers at a certain stage. Also, small islet-like cell clusters (ICCs) have been reported to originate in the vicinity of the ductal epithelium [20]. As presented in Fig. 4c, we observed ICC structures next to ductal cells in both STZ- and exendin-4-treated mice.

\section{a}
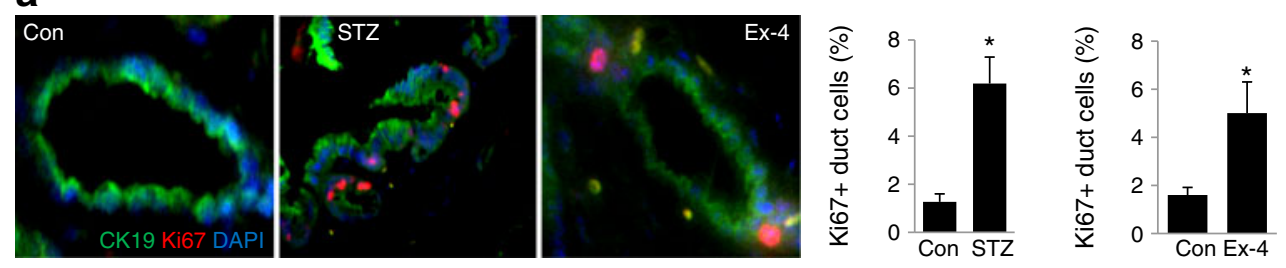

\section{b}
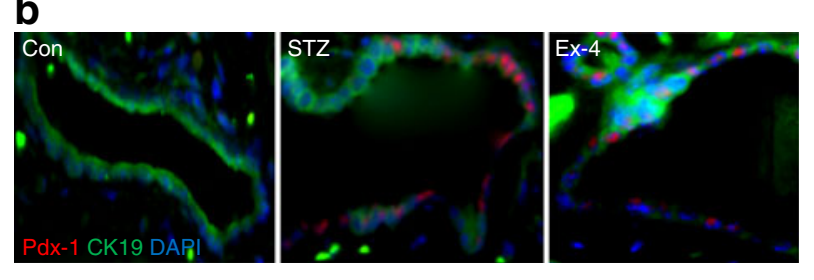

c
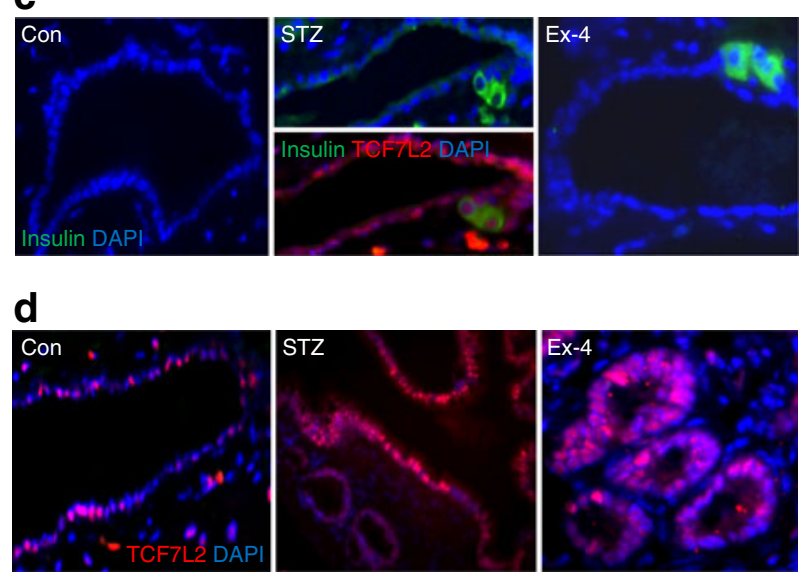
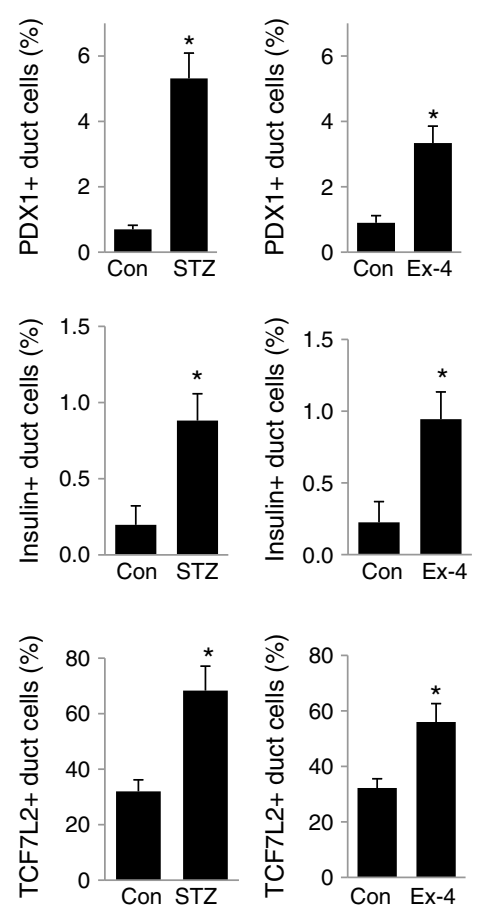

Fig. 4 Increased TCF7L2 levels is associated with ductal epithelial cell proliferation and differentiation in STZ- and exendin-4-treated mice. C57Bl/6 mice were injected i.p. with either exendin-4 (Ex-4, $10 \mathrm{nmol} / \mathrm{kg}), \mathrm{STZ}(90 \mathrm{mg} / \mathrm{kg})$ or vehicle (control, Con) and their pancreases were analysed after 7 days. (a) Proliferation of ductal epithelial cells was measured by triple staining for CK19/Ki67/DAPI. (b) Representative pictures of $P d x 1$ expression observed within the CK19-positive ductal epithelium from controls, STZ- and exendin-4treated mice by triple staining for PDX1/CK19/DAPI. (c) Representative pictures of small ICCs originated in the vicinity of the ducts. ICCs were rarely found under control conditions. Insulin-positive cells within the duct were counted and quantified as the percentage of insulinpositive ductal cells. The insert (middle panel) shows that insulinpositive cells were TCF7L2 positive. (d) Tcf7l2 expression in the ductal epithelium (TCF7L2/DAPI) and quantification of TCF7L2positive ductal cells. Results of quantification are means \pm SE from ten mice per group in three independent experiments. Values are representative of five or six slides spanning the whole pancreas of each mouse. ${ }^{*} p<0.05$ compared with vehicle-injected control mice 
Quantification of the number of ICCs near the pancreatic ducts revealed five- and fourfold increased number of beta cells next to the duct in STZ- and exendin-4-treated mice, compared with control mice ( $p<0.005$; Fig. $4 \mathrm{c})$; all of these cells were TCF7L2-positive (see Fig. 4c, middle panel, insert).

Together with the appearance of PDX1-positive ductal epithelial cells and ICCs in STZ- and exendin-4-treated mice, significant 2.1- and 1.7-fold upregulation of TCF7L2 in ductal epithelial cells was observed in STZ- and exendin4-treated mice, respectively, compared with control mice (Fig. $4 \mathrm{~d} ; p<0.05$ ). These observations indicate increased TCF7L2 levels during new beta cell formation.

Increased TCF7L2 levels correlate with insulin-positive ductal epithelial cells in patients with type 2 diabetes After we observed an association of TCF7L2 levels with ductal proliferation and beta cell formation in the ductal vicinity, we investigated whether such a correlation also exists in the human pancreas. Increased ductal proliferation in the pancreas in obesity and in patients with type 2 diabetes was reported recently [21].

In accordance with our observation in the STZ and exendin-4 mouse models, insulin-positive ductal cells were also found in pancreatic sections from autopsy from patients with type 2 diabetes $(n=6)$, but were rarely found in nondiabetic individuals $(n=7$, Fig. 5 a; 7.5 -fold increase in the percentage of insulin-positive ductal cells). A significant increase in double-positive cells for PDX1 and CK19 was also observed in type 2 diabetes (Fig. 5 b; fourfold increase in the percentage of PDX1-positive ductal cells in type 2 diabetes, compared with non-diabetic controls). In parallel to the increased number of insulin-positive cells around the duct as well as PDX1-positive ductal cells in type 2 diabetes, we observed a 1.9-fold increased in TCF7L2positive ductal epithelial cells in patients with type 2 diabetes ( $p>0.01$; Fig. 5 c). In contrast, inter-islet TCF7L2 levels were almost undetectable in patients with type 2 diabetes [6].

Overexpression of TCF7L2 could trigger ductal epithelial cell to beta cell conversion in vitro Despite the increased ductal TCF7L2 levels, an adaptation of beta cell mass to insulin demand fails to occur in patients with type 2 diabetes. Nevertheless, we tested the possibility of whether overexpression of TCF7L2 in vitro might trigger beta cell formation in human exocrine tissue.

Pancreatic exocrine tissue is composed of acinar and ductal cells, which are both potential progenitor cells, theoretically capable of differentiating into beta cells [22, 23]. Human exocrine cells obtained from human islet isolations were transfected with plasmids for TCF7L2 or GFP; transfection efficiency of the acinar cells was $70 \%$ based
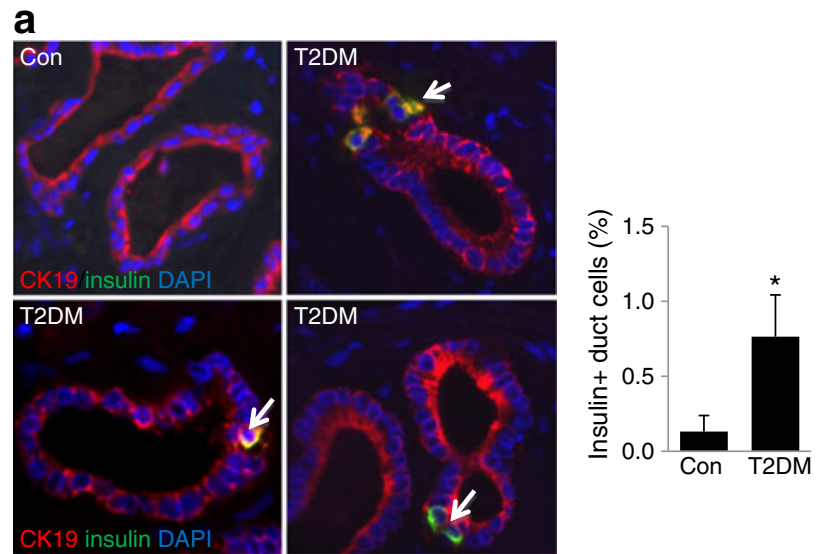

\section{b}
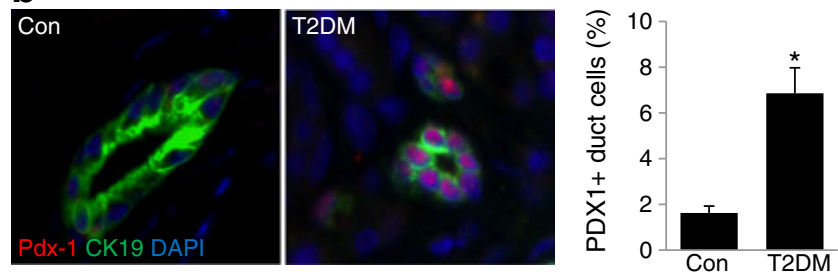

C
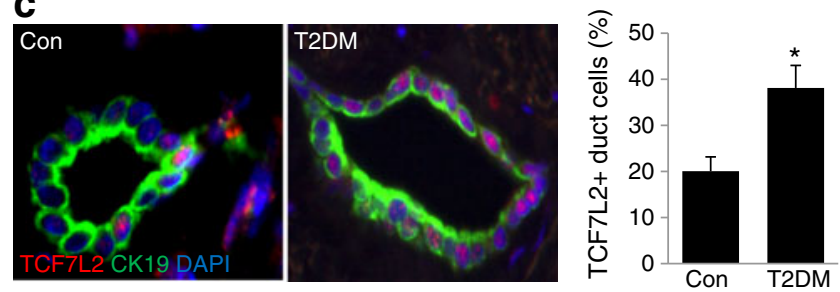

Fig. 5 Increased TCF7L2 expression correlates with ductal epithelium differentiation into beta cells in patients with type 2 diabetes mellitus. (a) Representative triple stainings for CK19/insulin/DAPI in human pancreatic sections from six poorly controlled patients with type 2 diabetes (T2DM; $n=6$ ) and seven healthy controls (Con; $n=7$ ) and quantification of the percentage of insulin-positive/CK19-positive cells. (b) Representative photographs of $P D X 1$ expression observed within the CK19-positive ductal epithelium from patients with type 2 diabetes and quantification of PDX1-positive/CK19 double-positive cells. (c) TCF7L2 expression levels in ductal epithelium were measured by quantification of TCF7L2-positive/CK19 double-positive cells. Results of quantification are means \pm SE. A total of 2,230 \pm 130 ductal cells were counted per pancreas for each analyte. Values are representative of two or three slides spanning the whole pancreas of each case. ${ }^{*} p<0.05$ compared with controls

on GFP level (data not shown). Ductal cells formed isletlike clusters, independent of the treatment condition. $T C F 7 L 2$ overexpression significantly increased proliferation of ductal epithelial cells (4.1-fold induction compared with GFP-transfected control, $p<0.005$; Fig. 6a), together with the induction of PDX1 and neurogenin 3 (NGN3) (4.2-/5.1fold increase in the percentage of PDX1/NGN3-CK19 double-positive cells, respectively, compared with GFPtransfected ductal cells; $p<0.05$; Fig. $6 \mathrm{~b}, \mathrm{c}$ ). Consequently, $T C F 7 L 2$ overexpression led to insulin production within the 
a
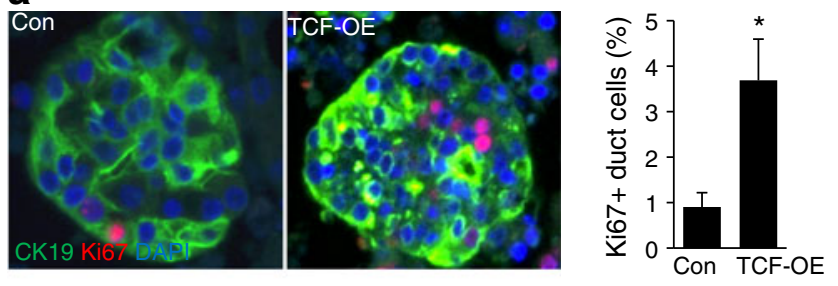

b
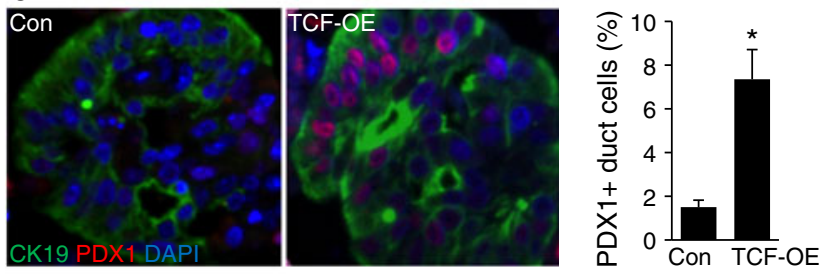

C
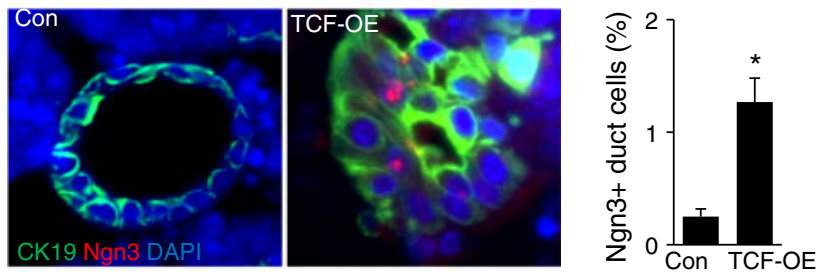

d
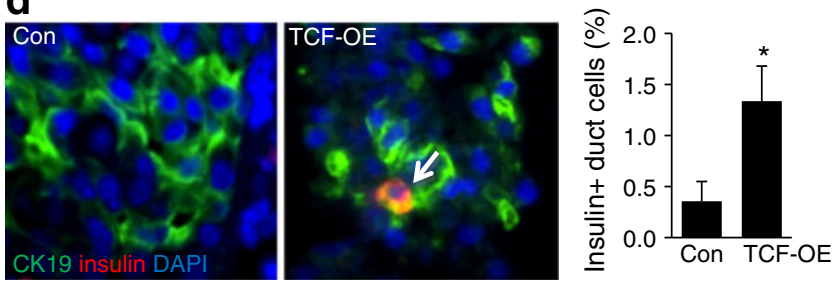

e

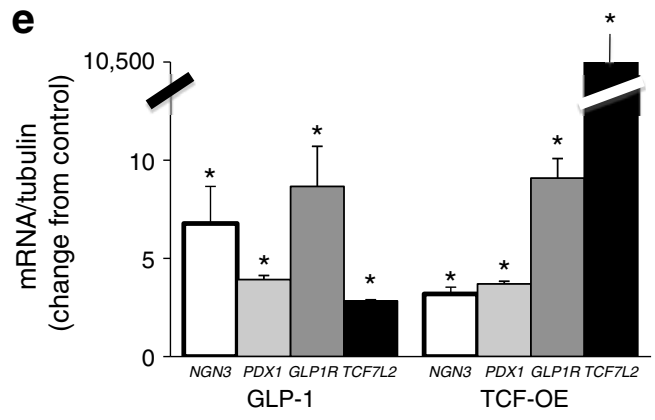

ductal epithelial cell cluster. While almost all CK19-positive cells were negative for insulin, a fourfold increase in insulin/ CK19 double-positive cells was observed in TCF7L2-overexpressing cells ( $p<0.05$, Fig. $6 \mathrm{~d})$.

The incretin hormone GLP1 and its analogue exendin-4 stimulate beta cell neogenesis [11]. GLP1R is expressed in ductal cells [18], and we applied GLP1 as a positive control of beta cell neogenesis. The RT-PCR results displayed in Fig. 6e demonstrate that both GLP1 treatment and TCF7L2 overexpression increased $P d x 1$ and $N g n 3$ mRNA levels, as
Fig. 6 Overexpression of $T C F 7 L 2$ could trigger ductal epithelial cell to beta cell conversion in vitro. TCF $7 L 2$ was overexpressed for 4 days in human pancreatic exocrine tissue and embedded in paraffin for immunohistochemical analysis. (a) Triple staining of CK19/Ki67/ DAPI and quantification of the percentage of Ki67/CK19 doublepositive cells. (b) Triple staining of CK19/PDX1/DAPI and quantification of the percentage of PDX1/CK19 double-positive cells. (c) Triple staining of CK19/NGN3/DAPI and quantification of the percentage of NGN3/CK19 double-positive cells. (d) A representative picture displaying insulin/CK19 double-positive ductal epithelial cells, and quantification of the percentage of insulin/CK19 double-positive cells. (e) mRNA was isolated from transfected and GLP1-treated exocrine cells after 4 days and RT-PCR analyses of NGN3, PDX1, GLP1R and $T C F 7 L 2$ were performed. The levels of gene expression were normalised to tubulin and cyclophilin (with similar results) and presented as change from control. Results are means \pm SE from three different experiments with three donors. A total of 5,335 \pm 245 ductal cells were counted for each analyte. ${ }^{*} p<0.05$ compared with control. Con, control; TCF-OE, TCF overexpression

well as Glp1r and Tcf7l2 mRNA expression, which confirms previous data from human islets showing a link between GLP1 and TCF7L2 signals [6].

TCF7L2 stimulates ductal cell differentiation through the JAK2/STAT3 pathway Although the signals that mediate ductal epithelial cell differentiation and beta cell neogenesis are still largely unknown, the JAK2/STAT3 pathway has been shown to be involved in beta cell neogenesis from acinar cells [22]. First, we examined STAT3 content in the pancreas of the STZ diabetic mouse model. Under control conditions, p-STAT3 was absent from the pancreas (Fig. 7a). In contrast, p-STAT3-positive beta cells as

Fig. 7 TCF7L2 stimulates ductal cell differentiation through the JAK2/STAT3 pathway. (a-c) Triple staining for p-STAT3/insulin/ DAPI in mouse pancreatic sections from STZ- and vehicle-injected mice both in islets and ductal cells (a) and in tissue sections of human exocrine cells transfected with TCF7L2 or control (b). STAT3 phosphorylation and translocation of total STAT3 (c) to the nucleus occurred only in TCF7L2-transfected cells. (d) Activation of STAT3 in isolated mouse exocrine cells and inhibition of STAT3 phosphorylation by AG490 were analysed by western blot analysis after 4 days of culture and treatment. The same blot was analysed for p-STAT3, total STAT3 (T-STAT3), p-AKT, TCF7L2 and actin after stripping, and densitometry analysis of band intensities was performed. Data are shown from three independent experiments. (e-g) mRNA was isolated from transfected and GLP1-treated exocrine cells with or without AG490 and RT-PCR analyses of Pdxl, insulin and Hnf6. (h) Activation of STAT3 in isolated human islets transfected with scrambled control siRNA, siTCF7L2, a control GFP plasmid or a TCF 72 plasmid. Protein and RNA analyses were performed after the 4-day culture period. (h) The same blot was analysed for p-STAT3, total STAT3 and actin after stripping and densitometry analysis of band intensities was performed. (i) The levels of gene expression were normalised to tubulin and actin (mouse) or cyclophilin (human) (with similar results) and presented as change of control. Analyses were performed in three independent experiments from three mouse isolations or from three different human islet donors. ${ }^{*} p<0.05$ compared with control, ${ }^{\dagger} p<0.05$ compared with same treatments without AG490. Grey bars, p-STAT3/ actin; black bars, total STAT3/actin. TCF-OE, TCF overexpression 
a
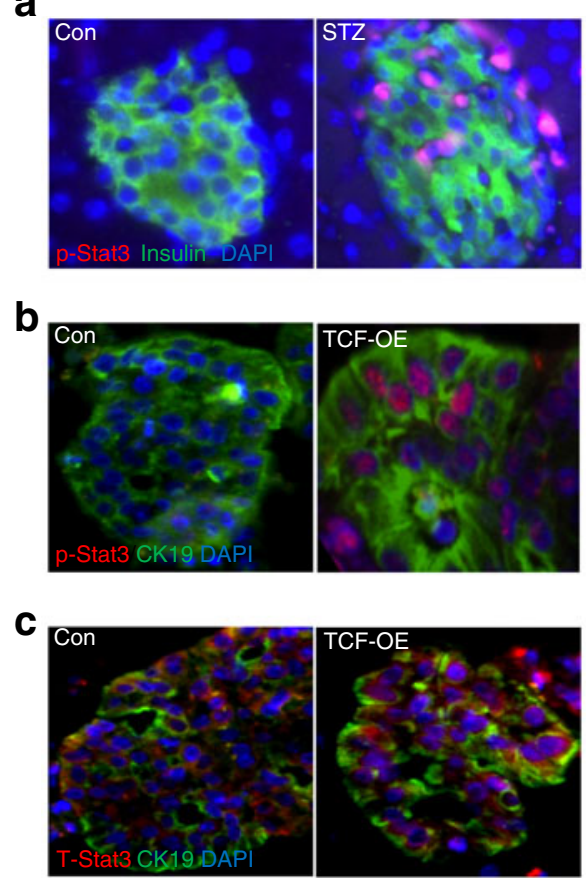

e
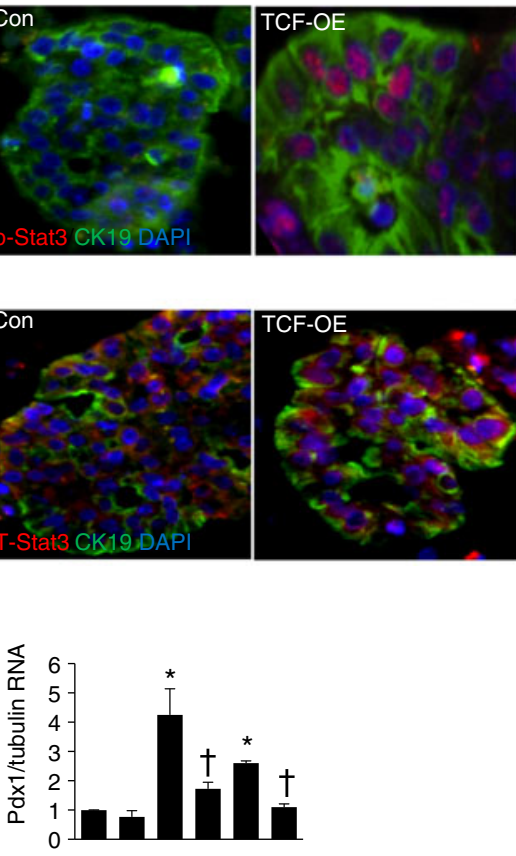
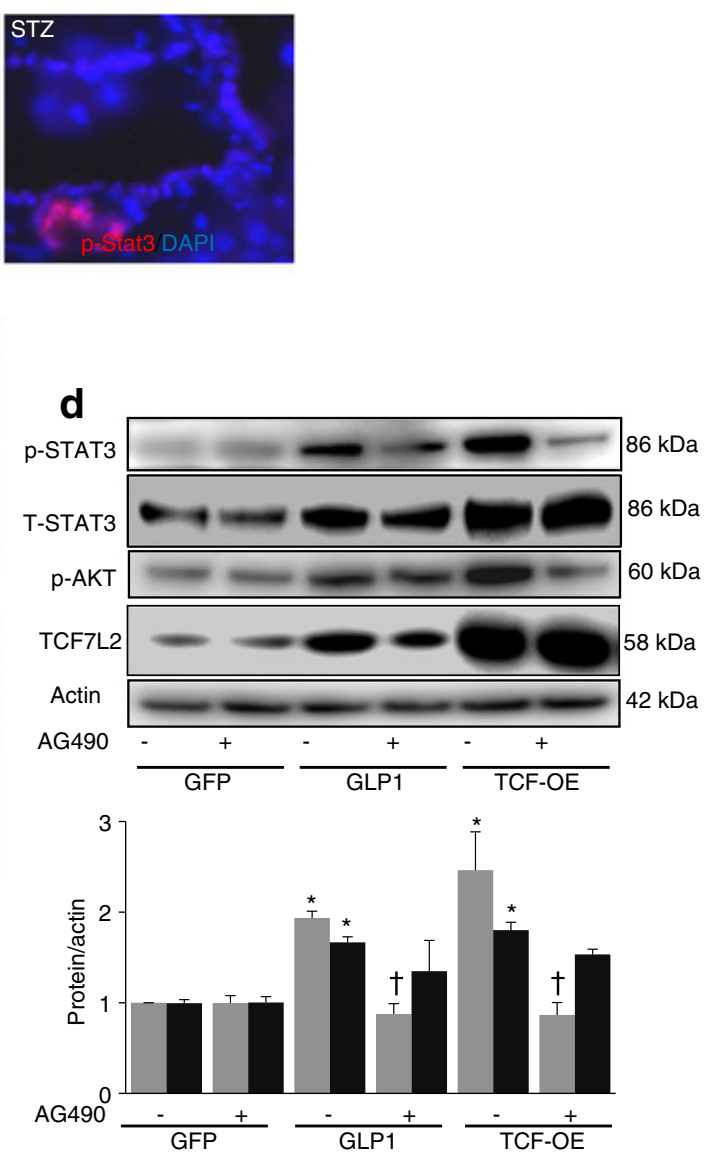

f

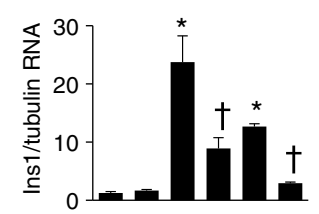

g
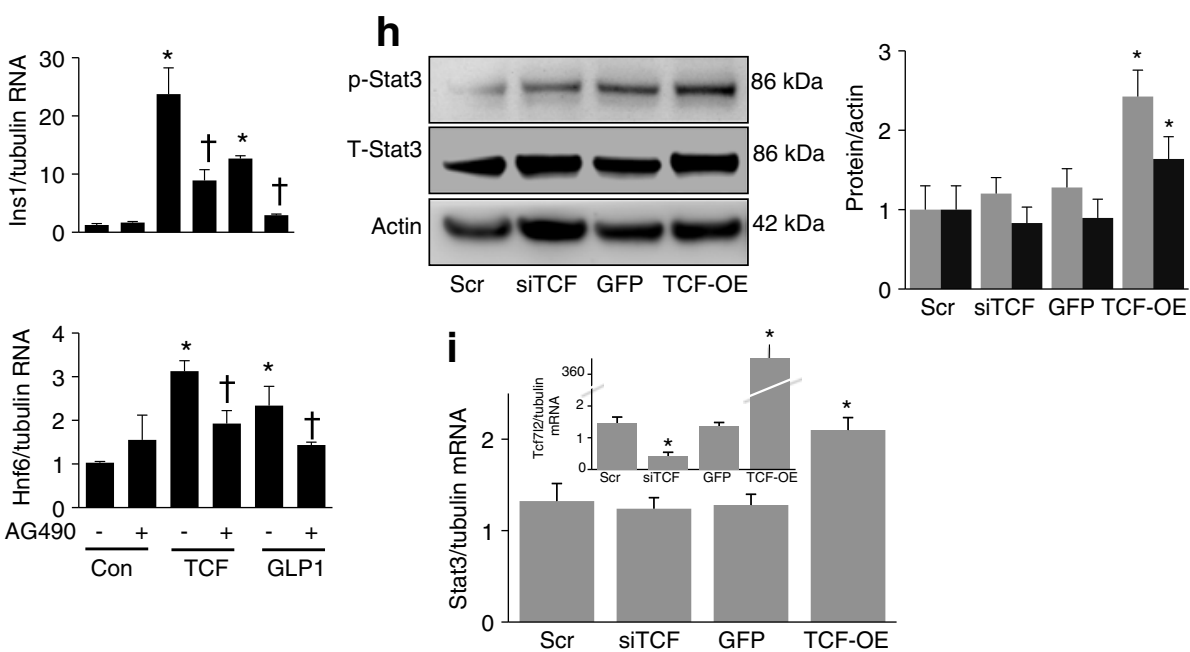

well as ductal cells were observed in STZ-treated mice (Fig. 7a). TCF7L2 overexpression in human exocrine cells induced STAT3 activation, while p-STAT3 was absent under control conditions (Fig. 7b). Total STAT3 was constitutively produced in ductal cells. In TCF7L2transfected cells, total STAT3 was increased and accumulated in the nucleus (Fig. 7c).
To quantify such changes and to confirm an effect of STAT3 on TCF7L2-induced beta-cell formation, we performed western blotting and RT-PCR with mouse exocrine pancreatic tissue. Islets were hand-picked and the remaining exocrine cells were exposed to AG490, a specific JAK2 inhibitor [24], to further clarify whether ductal epithelial cell differentiation induced by $T C F 7 L 2$ overexpression is 
JAK2/STAT3 dependent. GLP1, which is known to induce STAT3 phosphorylation, was used as positive control. In mouse pancreatic exocrine tissue, GLP1 as well as TCF7L2 overproduction (see western blot in Fig. 7d) induced strong phosphorylation of STAT3 (Fig. 7b, c). Also, and in confirmation with a previous report [25], total STAT3 levels were increased. The JAK2 inhibitor AG490 was associated with a significant reduction in GLP1-and TCF7L2-induced STAT3 phosphorylation. Downstream activation of AKT, which is induced by GLP1 and TCF7L2 in islets $[4,6,26]$ and linked to STAT3 signalling [27], was also blocked by the JAK2 inhibitor (Fig. 7d). While successful TCF7L2 overproduction could be confirmed by western blot analysis (upregulation of the major $58 \mathrm{kDa}$ band), GLP1 also induced TCF7L2 levels, which was inhibited by JAK2 inhibition, suggestive of a positive feedback loop.

Since STAT3 activation was responsible for AKT activation in mouse pancreatic exocrine cells, we investigated whether $T c f 7 l 2$ overexpression and GLP1 treatment could both induce islet transcription factors in a STAT3-dependent manner. GLP1 treatment and Tcf7l2 overexpression increased $P d x 1$ and insulin mRNA expression in isolated mouse exocrine cells compared with control (Fig. 7e-g). Hepatocyte nuclear factor-6 (onecut-1), which controls pancreatic endocrine differentiation at the precursor stage and regulates Ngn3 expression in the pancreas [28], was also increased by GLP1 and TCF7L2. In contrast, inhibition of STAT3 activation by AG490 treatment resulted in a significant reduction of $P d x 1$, insulin and Hnf6 mRNA in the treated exocrine cells, indicating that beta cell gene expression is controlled by JAK2/STAT3. In confirmation of the exocrine tissue experiments, TCF $7 L 2$ overexpression also induced p-STAT3 and total STAT3 protein (Fig. 7h) and Stat3 mRNA (Fig. 7i) expression in human isolated islets, while depleting TCF7L2 by siRNA had no effect (Fig. 7h, i), neither in islets nor in exocrine tissue.

\section{Discussion}

Loss of functional beta cells is the crucial event in the development of type 1 and 2 diabetes. Regeneration of beta cells is one promising approach to restore the deficit in beta cell mass in patients with diabetes, but has so far been difficult to achieve. Theoretically, new adult beta cells arise either through differentiation of endocrine stem or progenitor cells or by replication of existing beta cells [29, 30].

Pancreatic ductal epithelial cells, acinar cells, other endocrine cells (e.g. alpha or delta cells) and mesenchymal stromal cells from bone marrow have been identified as beta cell precursors [30]. In contrast, lineage-tracing studies in mice show that only the beta cell itself serves as a beta cell source through self-duplication [31], although this was recently not confirmed [32] and is challenged by the fact that alpha cells $[33,34]$, acinar cells $[35,36]$ and ductal cells [37] are also sources for new beta cell formation, the last of which has been confirmed in the current study. Another source of beta cells is facultative progenitors in regenerating pancreatic ducts [30]. Differences certainly exist between mice and humans. Therefore, we abandoned complex lineage-tracing approaches in mice in this study and rather compared the effects of TCF7L2 expression in mouse and human pancreatic cells.

We observed that TCF7L2 fosters pancreatic ductal epithelial cell proliferation and differentiation. Together with an induction of TCF7L2 expression, more proliferating ductal epithelial cells were found during beta cell regeneration. Small ICCs, which all produced TCF7L2, originated in the vicinity of the ductal epithelium. TCF7L2 in ductal cells was clearly induced in type 2 diabetes. In some ducts, almost all cells stained positive for TCF7L2. In line with previous data [21], we observed an induction of proliferation in these ductal cells in human type 2 diabetes.

The attempt of beta cell regeneration, as suggested by the presence of beta cells in the vicinity of ductal cells, together with TCF7L2 expression in human type 2 diabetes and in the diabetic STZ mouse model, seems to be insufficient to compensate for the high demand of new beta cells under diabetic conditions. Despite the increase in TCF7L2, an adaptation of beta cell mass to the insulin demand fails to occur in type 2 diabetes, as well as in our experimental conditions of beta cell destruction. In addition, in the animal models, where we found up to 70\% TCF7L2-positive ductal cells, only $1 \%$ was insulin positive. Higher ductal TCF7L2 production was observed in diabetic pancreases, but, in contrast, islet TCF7L2 is barely detectable [6]. Nevertheless, overexpression of TCF7L2 in vitro triggered new beta cell formation in human exocrine tissue. One could speculate that the increase of TCF7L2 achieved in vivo may not be enough to maintain a sufficient beta cell mass. In contrast, TCF7L2 levels achieved by plasmid overexpression are much higher than the physiological increase, which occurred in vivo, and such high TCF7L2 levels could trigger beta cell regeneration.

Insufficient adaptation in the beta cell in response to increased demand was also observed under the HFD/highsucrose ('Surwit') diet. While mice showed increased beta cell mass under the HFD/high-sucrose diet at up to 8 weeks, longer exposure resulted in further metabolic deterioration together with insufficient mass adaptation. TCF7L2 levels remained high at conditions of beta cell mass compensation (see [17]), but suddenly decreased to levels lower than under ND treatment when the diet was given for 12 weeks or longer. Similar defects in beta cell adaptation occurred in older mice. While young mice could increase beta cell mass in response to diet, old mice completely failed to increase 
their beta cell mass and showed further impaired glucose tolerance as well as a reduction in $T c f 7 l 2$ expression. Again, the physiological TCF7L2 increase in vivo failed to trigger long-term beta cell compensation.

The signalling pathways that promote duct cell differentiation and beta cell neogenesis are not clearly understood. Growth factors such as epidermal growth factor in combination with gastrin [38], IGF, TGF-beta [22, 39] and the acinar cell product known as islet neogenesis-associated protein [40] foster beta cell growth. The activation of the JAK2/STAT3 pathway occurs during generation of beta cells [22]. A functional TCF-binding element was detected in the STAT3 promoter, and TCF7L2 binds specifically to it [25]; in addition, STAT-Wnt interactions have been previously reported in other cells $[24,25]$. Here, we show that STAT3 mediates the effect of TCF7L2 and GLP1 on pancreatic exocrine cells in vitro and shows common intracellular pathways of TCF7L2 and GLP1. STAT3 activation seems to be essential for the differentiation of exocrine cells into beta cells, since inhibition of STAT3 significantly decreased beta cell-specific markers at the transcript level.

TCF7L2 overexpression increased Stat 3 mRNA. In contrast, downregulation of TCF7L2 by siRNA failed to affect STAT3; no effect was seen on p-STAT3, total STAT3 or mRNA levels. Since STAT3 is a direct target of the betacatenin/TCF pathway, we would have expected STAT3 downregulation by TCF7L2 depletion. Using siRNAs, we did not achieve full TCF7L2 depletion; the remaining TCF7L2 could still have maintained STAT3 levels. On the other hand, it is possible that further stimulation of the Wnt pathway is necessary to enhance STAT3; thus, at basally low levels of both TCF7L2 and p-STAT3, no effect could be observed. The major downstream signal of Wnt is betacatenin, which is translocated to the nucleus to switch on Wnt target genes. We have shown also that TCF7L2 upregulation activates beta-catenin and its target genes [15]. In turn, activated beta-catenin enhances STAT3 expression [25]. Thus, it is possible that the activation of the Wnt pathway is necessary for STAT3 activation, which is not manipulated by TCF7L2 downregulation. However, the key question-how TCF7L2 overexpression affects STAT3 phosphorylation - remains unanswered, it is very likely that this involves activation of another kinase or the inactivation of a phosphatase. Further investigations are necessary to explain this effect in detail. In addition, whether different TCF7L2 splice variants, which are present in various tissues including islets [15, 41-45], are also present in ductal cells and whether they have differential effects on ductal cell replication and the formation of beta cell clusters next to the duct is not known and also remains to be elucidated.

In conclusion, our findings imply a correlation of $T C F 7 L 2$ expression and beta cell regeneration as well as proliferation. TCF7L2 could trigger differentiation from ductal epithelial cells into beta cells in vitro. Our data support TCF7L2 as a new target for diabetes treatment to promote new beta cell formation.

Acknowledgements We thank J. Bergemann for excellent technical assistance and F. Paroni and A. Ardestani (all University of Bremen, Bremen, Germany) for the critical discussion of the paper.

Funding This work was supported by the European Foundation for the Study of Diabetes, the Chinese Diabetes Society, Lilly Research Fellowship, the University of Bremen Postdoctoral Research Program, the Natural Science Foundation of China (Grant No. 81102488), the German Research Foundation (DFG, MA4172/1-1) and the European Research Council.

Human islets were provided through the JDRF award 31-2008-413 (ECIT Islet for Basic Research program) and through the Integrated Islet Distribution Program, administered by the Administrative Bioinformatics Coordinating Center (ABCC), and supported by $\mathrm{Na}-$ tional Center for Research Resources (NCRR), National Institute of Diabetes and Digestive and Kidney Diseases (NIDDK), JDRF and the Chicago Diabetes Project. Human pancreatic sections were from the National Disease Research Interchange, supported by the National Institutes of Health.

Duality of interest The authors declare that there is no duality of interest associated with the manuscript.

Contribution statement LS, KZ, GG and KM designed the study, and performed and analysed research. JKC, FP and JO contributed new reagents or analytical tools and interpreted the data. All authors contributed to the writing of the paper and have approved the final version.

\section{References}

1. Grant SF, Thorleifsson G, Reynisdottir I et al (2006) Variant of transcription factor 7-like 2 (TCF7L2) gene confers risk of type 2 diabetes. Nat Genet 38:320-323

2. Rulifson IC, Karnik SK, Heiser PW et al (2007) Wnt signaling regulates pancreatic beta cell proliferation. Proc Natl Acad Sci USA 104:6247-6252

3. Figeac F, Uzan B, Faro M et al (2010) Neonatal growth and regeneration of beta-cells are regulated by the Wnt/beta-catenin signaling in normal and diabetic rats. Am J Physiol Endocrinol Metab 298:E245-E256

4. Shu L, Sauter NS, Schulthess FT et al (2008) Transcription factor 7-like 2 regulates beta-cell survival and function in human pancreatic islets. Diabetes 57:645-653

5. Loder MK, da Silva XG, McDonald A, Rutter GA (2008) TCF7L2 controls insulin gene expression and insulin secretion in mature pancreatic beta-cells. Biochem Soc Trans 36:357-359

6. Shu L, Matveyenko AV, Kerr-Conte J et al (2009) Decreased TCF7L2 protein levels in type 2 diabetes mellitus correlate with downregulation of GIP- and GLP1 receptors and impaired betacell function. Hum Mol Genet 18:2388-2399

7. da Silva Xavier G, Mondragon A, Sun G et al (2012) Abnormal glucose tolerance and insulin secretion in pancreas-specific Tcf712null mice. Diabetologia. doi:10.1007/s00125-012-2600-7

8. Schafer SA, Tschritter O, Machicao F et al (2007) Impaired glucagon-like peptide-1-induced insulin secretion in carriers of 
transcription factor 7-like 2 (TCF7L2) gene polymorphisms. Diabetologia 50:2443-2450

9. Drucker DJ (2006) The biology of incretin hormones. Cell Metab 3:153-165

10. Anastasi E, Ponte E, Gradini R et al (1999) Expression of Reg and cytokeratin 20 during ductal cell differentiation and proliferation in a mouse model of autoimmune diabetes. Eur J Endocrinol 141:644-652

11. Desgraz R, Bonal C, Herrera PL (2011) Beta-cell regeneration: the pancreatic intrinsic faculty. Trends Endocrinol Metabol 22:34-43

12. Tschen SI, Dhawan S, Gurlo T, Bhushan A (2009) Age-dependent decline in beta-cell proliferation restricts the capacity of beta-cell regeneration in mice. Diabetes 58:1312-1320

13. Sauter NS, Schulthess FT, Galasso R, Castellani LW, Maedler K (2008) The antiinflammatory cytokine interleukin-1 receptor antagonist protects from high-fat diet-induced hyperglycemia. Endocrinology 149:2208-2218

14. Schulthess FT, Paroni F, Sauter NS et al (2009) CXCL10 impairs beta cell function and viability in diabetes through TLR4 signaling. Cell Metab 9:125-139

15. Le Bacquer O, Shu L, Marchand M et al (2011) TCF7L2 splice variants have distinct effects on $\{$ beta\}-cell turnover and function. Hum Mol Genet 20:1906-1915

16. Ardestani A, Sauter NS, Paroni F et al (2011) Neutralizing interleukin-1beta (IL-1beta) induces beta-cell survival by maintaining PDX1 nuclear localization. J Biol Chem 286:17144-17155

17. Glas R, Sauter NS, Schulthess FT et al (2009) Purinergic P2X7 receptors regulate secretion of interleukin-1 receptor antagonist and beta cell function and survival. Diabetologia 52:1579-1588

18. Xu G, Stoffers DA, Habener JF, Bonner-Weir S (1999) Exendin-4 stimulates both beta-cell replication and neogenesis, resulting in increased beta-cell mass and improved glucose tolerance in diabetic rats. Diabetes 48:2270-2276

19. Uzan B, Figeac F, Portha B, Movassat J (2009) Mechanisms of KGF mediated signaling in pancreatic duct cell proliferation and differentiation. PLoS One 4:e4734

20. Lee JH, Jo J, Hardikar AA, Periwal V, Rane SG (2010) Cdk4 regulates recruitment of quiescent beta-cells and ductal epithelial progenitors to reconstitute beta-cell mass. PLoS One 5:e8653

21. Butler AE, Galasso R, Matveyenko A et al (2010) Pancreatic duct replication is increased with obesity and type 2 diabetes in humans. Diabetologia 53:21-26

22. Baeyens L, Bonne S, German MS et al (2006) Ngn3 expression during postnatal in vitro beta cell neogenesis induced by the JAK/ STAT pathway. Cell Death Differ 13:1892-1899

23. Gmyr V, Kerr-Conte J, Belaich S et al (2000) Adult human cytokeratin 19-positive cells reexpress insulin promoter factor 1 in vitro: further evidence for pluripotent pancreatic stem cells in humans. Diabetes 49:1671-1680

24. Liu YC, Lai WC, Chuang KA et al (2010) Blockade of JAK2 activity suppressed accumulation of beta-catenin in leukemic cells. J Cell Biochem 111:402-411

25. Yan S, Zhou C, Zhang W et al (2008) beta-Catenin/TCF pathway upregulates STAT3 expression in human esophageal squamous cell carcinoma. Cancer Lett 271:85-97

26. Welters HJ, Kulkarni RN (2008) Wnt signaling: relevance to betacell biology and diabetes. Trends Endocrinol Metabol 19:349-355

27. Tian Y, Zhang W, Xia D et al (2011) Postconditioning inhibits myocardial apoptosis during prolonged reperfusion via a JAK2STAT3-Bcl-2 pathway. J Biomed Sci 18:53
28. Jacqueminet S, Briaud I, Rouault C, Reach G, Poitout V (2000) Inhibition of insulin gene expression by long-term exposure of pancreatic beta cells to palmitate is dependent on the presence of a stimulatory glucose concentration. Metabolism 49:532-536

29. Hao E, Tyrberg B, Itkin-Ansari P et al (2006) Beta-cell differentiation from nonendocrine epithelial cells of the adult human pancreas. Nat Med 12:310-316

30. Bonner-Weir S, Weir GC (2005) New sources of pancreatic betacells. Nat Biotechnol 23:857-861

31. Dor Y, Brown J, Martinez OI, Melton DA (2004) Adult pancreatic beta-cells are formed by self-duplication rather than stem-cell differentiation. Nature 429:41-46

32. Nakamura K, Minami K, Tamura K et al (2011) Pancreatic betacells are generated by neogenesis from non-beta-cells after birth. Biomed Res 32:167-174

33. Thorel F, Nepote V, Avril I et al (2010) Conversion of adult pancreatic alpha-cells to beta-cells after extreme beta-cell loss. Nature 464:1149-1154

34. Collombat P, Xu X, Ravassard P et al (2009) The ectopic expression of Pax 4 in the mouse pancreas converts progenitor cells into alpha and subsequently beta cells. Cell 138:449-462

35. Bertelli E, Bendayan M (1997) Intermediate endocrine-acinar pancreatic cells in duct ligation conditions. Am J Physiol 273: C1641-C1649

36. Gu D, Arnush M, Sarvetnick N (1997) Endocrine/exocrine intermediate cells in streptozotocin-treated Ins-IFN-gamma transgenic mice. Pancreas 15:246-250

37. Bonner-Weir S, Inada A, Yatoh S et al (2008) Transdifferentiation of pancreatic ductal cells to endocrine beta-cells. Biochem Soc Trans 36:353-356

38. Suarez-Pinzon WL, Lakey JR, Brand SJ, Rabinovitch A (2005) Combination therapy with epidermal growth factor and gastrin induces neogenesis of human islet \{beta\}-cells from pancreatic duct cells and an increase in functional \{beta\}-cell mass. J Clin Endocrinol Metab 90:3401-3409

39. Shin JA, Hong OK, Lee HJ et al (2011) Transforming growth factor-beta induces epithelial to mesenchymal transition and suppresses the proliferation and transdifferentiation of cultured human pancreatic duct cells. J Cell Biochem 112:179-188

40. Rafaeloff R, Pittenger GL, Barlow SW et al (1997) Cloning and sequencing of the pancreatic islet neogenesis associated protein (INGAP) gene and its expression in islet neogenesis in hamsters. J Clin Invest 99:2100-2109

41. Duval A, Busson-Leconiat M, Berger R, Hamelin R (2000) Assignment of the TCF-4 gene (TCF7L2) to human chromosome band 10q25.3. Cytogenet Cell Genet 88:264-265

42. Osmark P, Hansson O, Jonsson A et al (2009) Unique splicing pattern of the TCF7L2 gene in human pancreatic islets. Diabetologia 52:850-854

43. Prokunina-Olsson L, Kaplan LM, Schadt EE, Collins FS (2009) Alternative splicing of TCF7L2 gene in omental and subcutaneous adipose tissue and risk of type 2 diabetes. PLoS One 4:e7231

44. Prokunina-Olsson L, Welch C, Hansson O et al (2009) Tissuespecific alternative splicing of TCF7L2. Hum Mol Genet 18:37953804

45. Weise A, Bruser K, Elfert S et al (2010) Alternative splicing of Tcf712 transcripts generates protein variants with differential promoter-binding and transcriptional activation properties at Wnt/ beta-catenin targets. Nucleic Acids Res 38:1964-1981 